\title{
Editorial
}

Nephrology

\section{Do the Eyes Reveal More Than Scleral Icterus in Sickle Cell Disease?}

\author{
Corinne A. Pittman Courtney D. Fitzhugh
}

Sickle Cell Branch, NHLBI, NIH, Bethesda, Md., USA

Sickle cell disease (SCD) is an autosomal recessive disorder that arises from a single nucleotide mutation in the $\beta$-globin gene of hemoglobin. This change promotes hemoglobin $S$ polymerization upon deoxygenation and results in the characteristic sickled shape of red blood cells. Common characteristics of SCD include anemia, ongoing hemolysis and a spectrum of complications impacting multiple organs. Anemia, caused by recurring hemolysis, contributes to more chronic consequences of SCD including functional renal damage and necrosis [1].

Because the renal oxygen consumption rate is high, the kidney is especially sensitive to vaso-occlusion-induced hypoxia. Red blood cells exhibit a higher propensity to sickle in the renal medulla due to its hypoxic and acidotic ambient conditions [2]. Furthermore, recurrent episodes of hemoglobin S polymerization and red blood cell sickling alter the rheological properties of the erythrocyte and lead to increased adhesiveness of the sickled cells to the endothelium [3]. Therefore, patients with SCD display many structural and functional renal abnormalities that are observed from the glomerulus to the papillary tip. The most common manifestation of glomerular injury in SCD is albuminuria, occurring in $26-68 \%$ of adults with SCD who are $\geq 21$ years of age, and $4.5-26 \%$ of them are younger patients [4]. Patients may then go on to develop nephrotic syndrome, chronic renal failure and end-stage renal disease. Renal insufficiency occurs in $4-18 \%$ of patients with SCD and leads to significant morbidity and early mortality $[2,3]$.

\begin{tabular}{ll}
\hline KARGER 125/s & $\begin{array}{l}\text { ( ) 2015 National Institutes of Health (NIH) } \\
\text { Published by S. Karger AG, Basel } \\
0250-8095 / 15 / 0416-0485 \$ 39.50 / 0\end{array}$ \\
$\begin{array}{l}\text { E-Mail karger@karger.com } \\
\text { www.karger.com/ajn }\end{array}$ &
\end{tabular}

Kord Valeshabad et al. [5] sought to investigate the association between conjunctival hemodynamic properties and albuminuria in subjects with SCD and preserved glomerular filtration rate. Conjunctival microcirculation imaging techniques were used to obtain conjunctival diameter and axial velocity measurements in 35 subjects with SCD, and these were compared to 10 healthy control individuals. As described in the previous studies, the authors used a high magnification optical imaging system (identified as EyeFlow ${ }^{\mathrm{TM}}$ ) to retrieve and derive frames of images that captured the movement of red blood cells within the conjunctival microcirculation $[5,6]$. A series of consecutive images were used to calibrate conjunctival velocity by measuring red blood cell movement along the centerline of the vessel [5]. Analysis of these frames resulted in rows of diagonal bands, varying in intensity, as a function of time [5-7]. The resulting data correlated with the flow of an aggregate of red blood cells [5]. Finally, conjunctival velocity readings were obtained by determining the slope of the most prominent bands. Conjunctival microcirculation imaging results were then related to urinary albumin excretion ratio (AER).

Conjunctival diameter and velocity measurements were observed in 179 and 432 conjunctival venules from the control and SCD subjects, respectively. The 35 subjects with SCD were assigned to 1 of the 3 groups according to mean conjunctival axial blood velocity $(\mathrm{V})$ readings that ranged from $<0.40$ to $>0.60 \mathrm{~mm} / \mathrm{s}$. The authors report significantly elevated AER in the high conjunctival 
velocity group, in comparison to those of the low and normal conjunctival velocity groups. While they also found a significant positive correlation between conjunctival velocity and albuminuria $(\mathrm{r}=0.47, \mathrm{p}=0.005)$, the authors note no statistically significant difference in AER between the normal and low conjunctival velocity groups and no significant correlation between conjunctival diameter and albuminuria. The AER in the high conjunctival velocity group falls within the macroalbuminuria range (defined as $300 \mathrm{mg} / \mathrm{g}$ creatinine) with a mean \pm SEM of $475 \pm$ $232 \mathrm{mg} / \mathrm{g}$ creatinine.

These findings indicate, for the first time, that elevated conjunctival velocity levels are associated with macroalbuminuria in patients with SCD. Although interesting, the findings are somewhat limited based on the crosssectional design. More specifically, they could not assess whether conjunctival velocity predicted whether patients would develop macroalbuminuria and whether further increases in conjunctival flow are associated with progressive disease. Also, because all patients with SCD do not develop albuminuria, it would be ideal to predict who would develop at least microalbuminuria based on slight increases in conjunctival velocity as compared to those who do not develop albuminuria so that preventive measures such as angiotensin-converting enzyme inhibitors could be considered. Still, their findings that patients with macroalbuminuria display significantly increased conjunctival velocity are intriguing and suggest that further studies should be performed.

\section{Disclosure Statement}

No conflict of interest is declared.

\section{References}

1 Scheinman JI: Sickle cell disease and the kidney. Nat Clin Pract Nephrol 2009;5:78-88.

2 Powars DR, Elliott-Mills DD, Chan L, Niland J, Hiti AL, Opas LM, et al: Chronic renal failure in sickle cell disease: risk factors, clinical course, and mortality. Ann Intern Med 1991; 115:614-620.

3 Ataga KI, Orringer EP: Renal abnormalities in sickle cell disease. Am J Hematol 2000;63: 205-211.
4 Ataga KI, Derebail VK, Archer DR: The glomerulopathy of sickle cell disease. Am J Hematol 2014;89:907-914.

5 Kord Valeshabad A, Wanek J, Zelkha R, Lim JI, Camardo N, Gaynes B, et al: Conjunctival microvascular haemodynamics in sickle cell retinopathy. Acta Ophthalmol 2015;93:e275e280.
6 Gaynes B, Teng PY, Wanek J, Shahidi M: Feasibility of conjunctival hemodynamic measurements in rabbits: reproducibility, validity, and response to acute hypotension. Microcirculation 2012;19:521-529.

7 Shahidi M, Wanek J, Gaynes B, Wu T: Quantitative assessment of conjunctival microvascular circulation of the human eye. Microvasc Res 2010;79:109-113. 